\title{
Endocytosis as a mode to regulate functional expression of two-pore domain potassium $\left(K_{2 P}\right)$ channels
}

\author{
Ita O'Kelly
}

Received: 20 September 2014 / Revised: 22 October 2014 / Accepted: 24 October 2014 /Published online: 22 November 2014

(C) The Author(s) 2014. This article is published with open access at Springerlink.com

\begin{abstract}
Two-pore domain potassium $\left(\mathrm{K}_{2 \mathrm{P}}\right)$ channels are implicated in an array of physiological and pathophysiological roles. As a result of their biophysical properties, these channels produce a background leak $\mathrm{K}^{+}$current which has a direct effect on cellular membrane potential and activity. The regulation of potassium leak from cells through $\mathrm{K}_{2 \mathrm{P}}$ channels is of critical importance to cell function, development and survival. Controlling the cell surface expression of these channels is one mode to regulate their function and is achieved through a balance between regulated channel delivery to and retrieval from the cell surface. Here, we explore the modes of retrieval of $\mathrm{K}_{2 \mathrm{P}}$ channels from the plasma membrane and observe that $\mathrm{K}_{2 \mathrm{P}}$ channels are endocytosed in both a clathrin-mediated and clathrin-independent manner. $\mathrm{K}_{2 \mathrm{P}}$ channels use a variety of pathways and show altered internalisation and sorting in response to external cues. These pathways working in concert, equip the cell with a range of approaches to maintain steady state levels of channels and to respond rapidly should changes in channel density be required.
\end{abstract}

Keywords $\mathrm{K}_{2 \mathrm{P}}$ channel - Endocytosis $\cdot$ Recycling $\cdot$ Clathrin · TWIK $\cdot$ TREK $\cdot$ TASK $\cdot$ TRESK $\cdot$ Potassium channel

\section{Introduction}

Cellular endocytosis was classically viewed as a mechanism for protein internalisation and destruction. The identification of multiple endocytic pathways with defined cellular destinations helped recognise endocytosis as not only a means of

\section{O’Kelly $(\bowtie)$}

Human Development and Health, Centre for Human Development,

Stem Cells and Regeneration, Faculty of Medicine, University of

Southampton, Southampton SO16 6YD, UK

e-mail: I.M.O'Kelly@southampton.ac.uk reducing the expression of membrane proteins but also a mechanism to enable their rapid recycling and redistribution $[13,28,78]$. Endocytosis is now understood to be central to the fine control of cell surface expression and function of many membrane proteins.

Expression of two-pore domain potassium $\left(\mathrm{K}_{2 \mathrm{P}}\right)$ channels on the cell surface is regulated at the transcriptional and posttranscriptional levels, via controlled biogenesis, sorting and trafficking [32, 65, 73]. These channels show constitutive activity once inserted into the plasma membrane and their surface expression directly impacts cell membrane potential by supporting $\mathrm{K}^{+}$leak from cells $[43,65,69]$. Consequently, changes to channel surface density will result in changes in $\mathrm{K}^{+}$ leak, membrane depolarisation and hence, cellular function and excitation. Furthermore, as the $15 \mathrm{~K}_{2 \mathrm{P}}$ family members show widespread tissue distribution and, as reviewed by others within this issue, are proposed to play roles in cellular mechanisms as diverse as chemoreception, adrenal development, cardiac function, pain, sleep and anaesthesia, the control of their surface density has the potential to impact an array of cellular physiological and pathophysiological processes $[16$, $46,47,90]$. Our understanding of the mechanisms which regulate delivery of members of the $\mathrm{K}_{2 \mathrm{P}}$ family to the cell surface has been elucidated over the last decade and is the focus of Renigunta et al. review (in this issue). Clearly, the recovery of $\mathrm{K}_{2 \mathrm{P}}$ channels from the plasma membrane is of equal importance and a molecular understanding of the interplay between various endocytic pathways and environmental triggers is vital to our understanding of their roles in cell regulation. To date, we have limited knowledge of the pathways used by many of the $\mathrm{K}_{2 \mathrm{P}}$ channels. This article will provide an overview of our current understanding of the predominant endocytic pathways utilised by ion channels and present recent evidence of endocytic pathway usage by members of the $\mathrm{K}_{2 \mathrm{P}}$ family, including $\mathrm{K}_{2 \mathrm{P}} 1.1$ (TWIK1), $\mathrm{K}_{2 \mathrm{P}} 2.1$ (TREK1), $\mathrm{K}_{2 \mathrm{P}} 3.1$ (TASK1) $\mathrm{K}_{2 \mathrm{P}} 9.1$ (TASK3) and 
$\mathrm{K}_{2 \mathrm{P}} 18.1$ (TRESK). Finally, using known criteria for recruitment of cargo into specific endocytic pathways, we speculate on likely modes of endocytosis of the remaining $\mathrm{K}_{2 \mathrm{P}}$ family members.

\section{Ion channel endocytosis}

Cells use various mechanisms to internalise plasma membrane proteins (Fig. 1), and many proteins are capable of being recruited to different endocytic pathways in response to environmental triggers or as a result of constitutive or stimulated endocytosis $[17,20,110]$. The primary congregation point for most internalised proteins is the Rab5 (Ras-related GTPase 5) positive early endosome [11, 64, 114]. From here, proteins can either transit to recycling endosomes and back to the plasma membrane or are sorted to late endosomes and finally to the lysosome for degradation [11, 12, 93]. Similarly, at the transGolgi network (TGN), proteins can shuttle to the plasma membrane or be diverted to endosomes [12, 54]. An ARF6 (a member of the family of ADP-ribosylation factor) positive compartment operates as an alternative route to direct delivery of cargo to the Rab5 positive early endosomes [15, 59, 95, 96]. Proteins targeted to the ARF6 positive compartment can be recycled directly back to the cell surface or pass from there to early endosomes. On the whole, the endocytic routes and subsequent trafficking pathways (degradation versus recycling) are specified by structural features or sorting motifs within the cytoplasmic domains of cargo proteins [11, 114]. These endocytic signals enable binding partners to target the protein into specific pathways. While the molecular details of these processes are still emerging, recognised motifs and modifications have been defined.

\section{Internalisation and intracellular sorting signals}

The most extensively studied endocytic pathway is clathrinmediated endocytosis (CME); however, a range of additional clathrin-independent endocytic pathways operate within different cell types and are proposed to account for a significant proportion of protein endocytosis [22, 28, 53, 75, 87]. Adaptor proteins (predominantly but not exclusively AP $1-4$ ) together with clathrin-associated sorting proteins (CLASPs) recruit cargo into clathrin-coated vesicles of the CME pathway [62, 87, 92, 113]. Recruitment relies on recognition of sorting motifs predominantly within the cytosolic termini of cargo protein. A tyrosine motif ( $Y X X \phi$; using single amino acid code $\mathrm{X}$ represents a variable residue and $\phi$ a hydrophobic residue) and a di-leucine [DE]XXXL [LI] motif in channel ctermini are recognised by clathrin adaptor protein AP-2 ( $\mu$ and $\alpha-\delta 2$ subunits, respectively) [11]. AP-2 binding facilitates recruitment to the clathrin bud and results in channel endocytosis and lysosomal targeting. AP-1 and AP-3 also recognise these motifs but play roles in bidirectional transport between TGN and endosomes and sorting to lysosome (for AP-3
Fig. 1 Ion channel endocytic pathways. Clathrin-mediated and clathrin-independent sorting pathways utilised by ion channels. Channels can be internalised by scission of clathrin-coated pits by action of dynamin to produce clathrincoated vesicles which can be sorted to endosomes, lysosomes and trans-Golgi network. Cargo internalised through clathrinindependent pathways can also be sorted to the same destinations following their shuffling to the early endosomes $\left(\mathrm{Rab}^{+}\right)$. Alternatively, cargo of the clathrin-independent pathway can enter $\mathrm{ARF}^{+}$recycling endosomes and return directly to the cell surface or transit to the early endosomes and into the endocytic pathway (recycling or late endosomes) from there. Prominent Rab proteins in each of the compartments are included. Arrows indicate possible direction of sorting between compartments

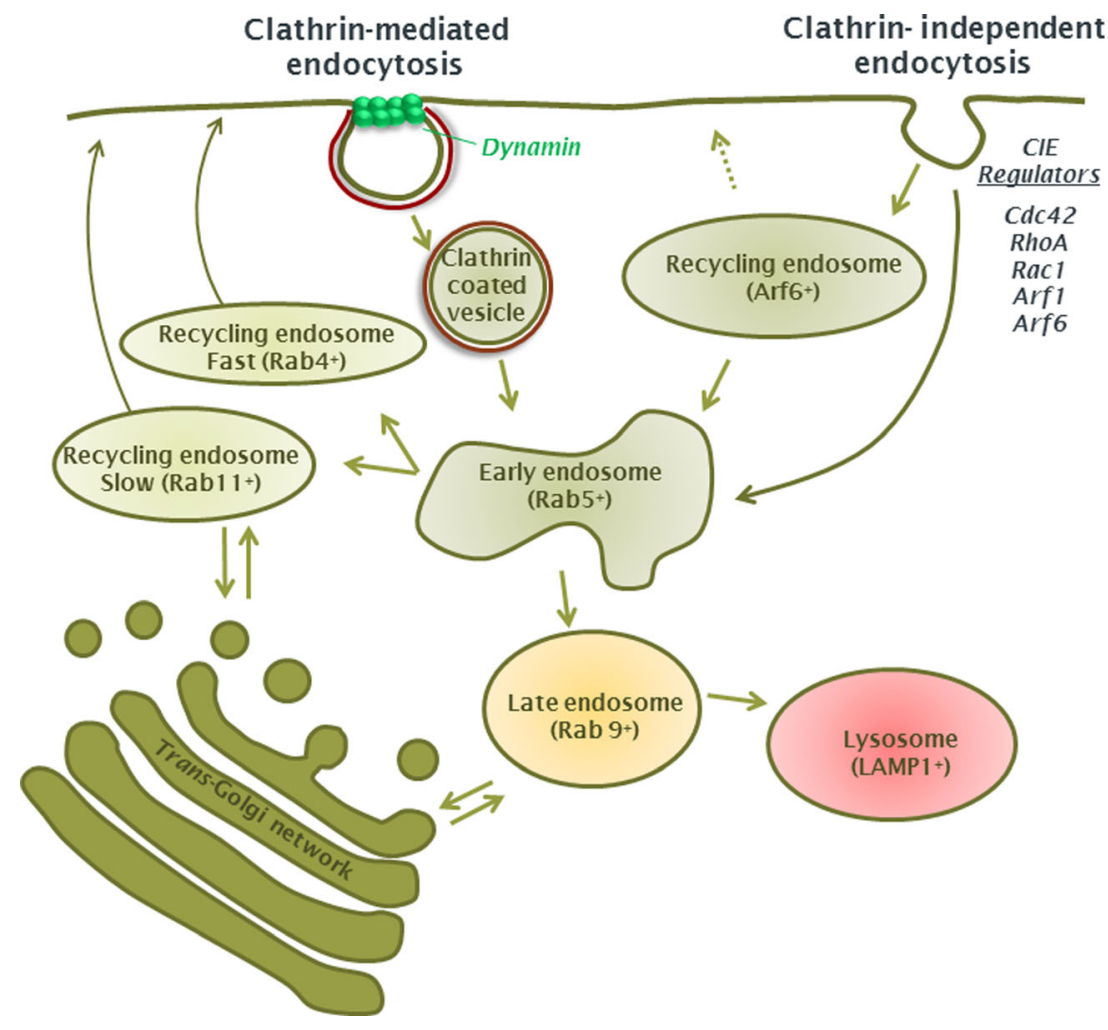


recruited cargo) $[104,109]$. A similar motif, DXXLL or acidic cluster/di-leucine motif, is recognised by another member of the ARF family (ARF1) which is localised to the TGN and endosomes and regulates membrane recruitment of AP1 and AP3 $[30,81]$. These motifs are thought not to be involved in cargo internalisation or recycling but likely enable sorting of transmembrane proteins from the TGN to endosomes.

Cargo bearing an alternative tyrosine motif ([FX]NPXY[FX]), as seen in Kir1.1, are also endocytosed through the CME pathway [11, 21,35]. Here, recruitment into clathrin-coated vesicles appears to be independent of AP-2 but depends on CLASP proteins which either contain a phosphotyrosine-binding (PTB) domain and associate with either of PTB proteins, Disabled-2 (Dab2) and the autosomal recessive hypercholesterolemia (ARH) protein which localise to clathrin-coated structures $[57,79,80]$. [FX]NPXY[FX] motifs are also recognised by sorting nexin (SNX) proteins, endocytic proteins which contain phox-homology (PX) domains selective for endosomal phosphatidylinositol 3phosphate (PtdIns(3)P) and function in cargo internalisation and endosomal sorting $[19,111,116]$.

\section{Clathrin-independent endocytosis}

While CME is recognised by its distinctive cytoplasmic coat and well-defined mechanism for selection of cell surface cargo, evidence supports the existence of additional endocytic routes with less distinctive pathways and cargo recruitment. Together these pathways are grouped by their lack of dependence on a clathrin coat and machinery and are termed clathrin-independent endocytosis (CIE). As these pathways have less distinct coated vesicles and adaptor proteins, to date, few cargo motifs have been exclusively associated with a single CIE pathway $[45,70]$. It is currently unclear how many CIE pathways exist and if incorporation into these pathways is via recruitment into vesicles or bulk release from plasma membrane [107]. Three general regulators of these pathways have been defined. CIE pathways are divided into those regulated by small GTPases ARF6, Cdc42/ARF1 and Rho A [29]. Most CIE pathways are dependent on actin and sensitive to plasma membrane cholesterol concentration [1, $45,82,107]$. Cholesterol levels play an important regulatory role in the function of small GTPase Cdc42, as well as the recruitment of cholesterol interacting membrane proteins (e.g. flotillins) which enhance some CIE pathways [6, 42, 82]. While CIE is often described as a non-selective process, internal sorting of CIE cargo is evident. ARF6 activity regulates post-endocytic trafficking of CIE cargo [34]. By activating phosphatidylinositol 4-phosphate 5-kinase ARF6 can increase phosphatidylinositol 4,5 bisphosphate (PIP2). Inactivation of ARF6 following internalisation results in reduced PIP2 levels and supports the fusion of endocytic vesicles with early endosomes (containing CME cargo) [51, $55,61]$. ARF6 activation is also required for recycling of CIE cargo usually from the recycling tubular endosomes back to the plasma membrane through activation of phospholipase D $[55,101]$. Indeed, ion channels containing acidic cluster (termed potassium acidic clusters or KAC) have been shown to be recruited into an ARF6-regulated recycling pathway [44]. Addition of KAC to cargo enables its rapid recycling to the plasma membrane via a route which bypasses the early endosome. ARF6, Rac, Ras or Sfc activation has also been implicated in plasma membrane ruffling and macropinocytosis $[60,97,120]$.

Until recently, caveolae were believed to represent a distinct CIE pathway and were proposed to regulate ion channel function by controlling their trafficking $[5,91]$. Recent data demonstrate that caveolae are static at the plasma membrane and caveosomes remain attached to the cell surface $[39,89]$. These developments suggest that caveolae may function in organising ion channel macrodomains; however, they appear not to enable channel endocytosis [39].

While it remains unclear whether cargo is actively selected at the plasma membrane or is released from retention to enable internalisation via CIE, evidence suggests that endocytosis of CIE cargo may occur by different pathways under different cellular conditions $[3,110]$.

\section{ARF6-dependent endocytosis is a key regulator of $K_{2 \mathrm{P}} 1.1$ (TWIK-1) surface expression}

The wild-type protein of the first mammalian member of the $\mathrm{K}_{2 \mathrm{P}}$ channel family, $\mathrm{K}_{2 \mathrm{P}} 1.1$ (two-pore domain weak-inwardly rectifying potassium channel or TWIK) achieves low levels of functional expression [65-67, 83]. Various explanations for this low channel function have been proposed including channel inhibition by SUMOylation or more recently the identification of a hydrophobic gate within the channel inner cavity which disrupts $\mathrm{K}^{+}$flux $[4,37,98]$. Channel removal from the cell surface will also negatively impact channel function and increasing evidence suggests that independently of biophysical properties of this channel; $\mathrm{K}_{2 \mathrm{P}} 1.1$ shows low levels of surface expression with a high level of regulation of its expression on the cell surface. Wang et al. provide evidence of $\mathrm{K}_{2 \mathrm{P}} 1.1$ expression within astrocytes but demonstrate that these channels are predominantly located within the cytoplasm [117]. In 2004, Decressac et al. examined subcellular localisation of $\mathrm{K}_{2 \mathrm{P}} 1.1$ in both adult mouse kidney and Madin-Darby canine kidney (MDCK) cells stably expressing the channel [26]. $\mathrm{K}_{2 \mathrm{P}} 1.1$ localised to a subapical cellular domain in the kidney and polarised MDCK cells, which was confirmed to be an apical recycling compartment by colocalisation with endobrevin (vesicle associate membrane protein or Vamp-8) a marker for recycling endosomes and 
the perinuclear and vesiculotubular compartments. In nonpolarised cells, $\mathrm{K}_{2 \mathrm{P}} 1.1$ localised to the equivalent perinuclear recycling compartment. A di-isoleucine motif in the cterminus of $\mathrm{K}_{2 \mathrm{P}} 1.1(\mathrm{I} 293,294)$ was demonstrated to be instrumental in channel internalisation. Mutation of I293 results in increased channel surface expression and current [36]. The motif either enhances delivery or enables internalisation of the channel. Evidence suggests that it is the latter, as pulse chase experiments show nascent wild-type channels with intact diisoleucine motifs being delivered to the cell surface and then rapidly $(<10 \mathrm{~min})$ recycled to subapical compartment [36]. Channels with mutated motifs remained on the cell surface. Investigation into the nature of the motif found that it operates in a manner comparable to the di-leucine motif ([DE]XXXL[LI]) which enables cargo endocytosis via the CME with the potential to be recognised by AP-1, AP-2 or AP-3 [114]. Interestingly, Feliciangeli et al. demonstrate that endocytosis enabled by the di-isoleucine in the c-terminus of $\mathrm{K}_{2 \mathrm{P}} 1.1$ is sensitive to the activity of the mechanochemical GTPase, dynamin, required for vesicle scission in CME [36]. However, a clear role for ARF6-dependent endocytosis is also reported [26]. Elegant experiments from the same group using active and inactive forms of the small $\mathrm{G}$ protein ARF6 demonstrate that ARF6 exchange factor EFA6 interacts with an overlapping region of $\mathrm{K}_{2 \mathrm{P}} 1.1$ in an ARF6 dependent manner [26]. Dominant negative ARF6 was shown to promote surface expression of $\mathrm{K}_{2 \mathrm{P}} 1.1$ [26, 59].

These findings suggest an interplay between the CME and CIE pathways with ARF6 enhancing CME [25, 61, 88]. D'Souza-Schorey et al. first reported this in 1995 when they observed that a constitutively active ARF6 mutant (ARF6Q67L) inhibited transferrin receptor internalisation while the inactive ARF6 (ARF6T27N) prevented its recycling to the plasma membrane [25]. A clear link between CME pathways and ARF6 is apparent. Indeed, an ARF6 GTPase activating protein (GAP), SMAP1, which converts ARF6 from GTP bound to an inactive GDP bound state, directly binds clathrin. Additionally ARF6-GTP has been proposed as a source of GTP for dynamin-dependent scission of clathrin buds [88]. Active ARF6 may also enable recruitment of AP2 to the plasma membrane due to its role in PIP2 production which could then recruit $\mathrm{K}_{2 \mathrm{P}} 1.1$ to clathrin coated pits via it cterminal di-isoleucine motif $[51,61]$.

The mode of interplay between the CME pathway and ARF6 for $\mathrm{K}_{2 \mathrm{P}} 1.1$ sorting has yet to be fully ascertained; however, it is clear that $\mathrm{K}_{2 \mathrm{P}} 1.1$ is internalised to a subapical compartment via di-isoleucine motif and is recycled in an ARF6-dependent manner, with the consequence of $\mathrm{K}_{2 \mathrm{P}} 1.1$ being sequestered below the cell surface $[26,36]$. This cellular strategy would explain the maintenance of a low level of this leak channel on the cell surface that could then be rapidly delivered to the plasma membrane or transported onto the endocytic pathway (early endosomes) in response to external cues. Indeed, activation of the serotonergic receptor results in increased $\mathrm{K}_{2 \mathrm{P}} 1.1$ surface expression in the wild-type protein but not when the di-isoleucine motif has been disrupted [36]. 5-HT has previously been demonstrated to inhibit entorhinal cortex neurons in a $\mathrm{K}_{2 \mathrm{P}} 1.1$-dependent manner [27]. These data provide insight into this mechanism and suggest that 5HT triggers the release of $\mathrm{K}_{2 \mathrm{P}} 1.1$ from the subapical recycling compartment increasing its cell surface expression and resulting in neuronal depolarisation. The molecular mechanisms of many aspects of these regulatory processes are still lacking significant detail but a clear role of endocytosis in the regulation of $\mathrm{K}_{2 \mathrm{P}} 1.1$ is undeniable.

\section{Does bulk endocytosis control surface expression of $K_{2 P} 18.1$ (TRESK)?}

An alternative strategy for neuronal cells to control the surface expression of potassium leak channels is proposed for $\mathrm{K}_{2 \mathrm{P}} 18.1$ (also TWIK-related spinal cord potassium channel or TRESK). $\mathrm{K}_{2 \mathrm{P}} 18.1$ exhibits predominantly neuronal expression and disruption of its function has been implicated in playing a role in migraine with aura [33, 63, 108]. TRESK contains a consensus site for the calcium-dependent phosphatase, calcineurin, within its large cytosolic loop between transmembrane domains 2 and 3 [24]. Calcineurin plays a role in activity-dependent bulk endocytosis (ADBE) in nerve termini [119]. While no direct experimental evidence has been provided for TRESK internalisation via ADBE in activated nerve termini, its recruitment to the complex and the indiscriminate nature of this endocytic pathway certainly supports the concept.

\section{$\mathrm{K}_{2 \mathrm{P}} 2.1$ binding partners impact channel plasma membrane density}

Following $\mathrm{K}_{2 \mathrm{P}} 2.1$ 's (TWIK-related potassium channel 1 or TREK-1) molecular and biophysical characterisation, it rapidly became recognised as an important regulator of neuronal function [84]. $\mathrm{K}_{2 \mathrm{P}} 1.1$ is implicated in depression, polymodal pain perception, diseases related to blood-brain barrier dysfunction and anaesthesia $[2,9,38,48,52,56]$. Due to the neurological physiology and pathophysiology it impacts, modes of long-term regulation of $\mathrm{K}_{2 \mathrm{P}} 2.1$ are particularly sought after. A-kinase anchoring protein (AKAP150), microtubule-associated protein (Mtap2) and neurotensin receptor 3 (NTSR3 also known as sortilin) have been identified as binding partners to $\mathrm{K}_{2 \mathrm{P}} 2.1[76,105,106]$. Both Mtap2 and NTSR 3 are proposed to act by altering channel density. While Mtap2 interaction with $\mathrm{K}_{2 \mathrm{P}} 2.1$ was shown to enhance channel density, it is unclear if this is due to enhanced delivery or reduced recovery at the plasma membrane [105]. NTSR3 
promotes endocytosis and lysosomal sorting of neuronal cargo $[18,115,118]$. Interaction of a partial propeptide of NTSR3 (referred to as Spadin) with $\mathrm{K}_{2 \mathrm{P}} 2.1$ resulted in $80 \%$ of the complex being observed within the cell [76]. The researchers propose that activation of NTSR3 (through application of Spadin) results in endocytosis of both receptor and channel with likely targeting to TGN or lysosomes. To date, only protein interactions and channel density reduction have been confirmed experimentally and the precise pathways and channel destination have yet to be determined.

\section{$K_{2 P} 3.1$ utilises both CME and CIE pathways}

$\mathrm{K}_{2 \mathrm{P}} 3.1$ (TWIK-related acid sensitive potassium channel 1 or TASK-1) and $\mathrm{K}_{2 \mathrm{P}} 9.1$ (TWIK-related acid sensitive potassium channel 3 or TASK-3) show a high degree of homology in sequence and biophysical properties with both channels sensitive to external $\mathrm{pH}$ and regulated by similar modulators $[8,31$, $58,99]$. These channels have been proposed to function as heterodimers in some cells and indeed the forward transport of both channels appears to undergo similar regulation through post-translational modification and binding partner recruitment $[23,41,71,72,85,86,100,103,121]$. However, when considering $\mathrm{K}_{2 \mathrm{P}} 3.1$ and $\mathrm{K}_{2 \mathrm{P}} 9.1$ internalisation and subsequent sorting, these channels appear to diverge in their regulation. As the c-termini of these channels have a critical role in channel sorting and the c-termini of $\mathrm{K}_{2 \mathrm{P}} 3.1$ and $\mathrm{K}_{2 \mathrm{P}} 9.1$ show only $34 \%$ homology, this divergence is not wholly unexpected.

Under unstimulated conditions, both $\mathrm{K}_{2 \mathrm{P}} 3.1$ and $\mathrm{K}_{2 \mathrm{P}} 9.1$ are internalised and appear within the early endosome within minutes of permitting endocytosis (through removal of temperature block) [71]. Quantification of the number of sizedefined vesicles containing either of the internalised channels enabled comparison of the transit of both channels through the endocytic system. At specific time points, a higher number ( $>50 \%$ increase) of endocytosed vesicles containing $\mathrm{K}_{2 \mathrm{P}} 9.1$ compared to $\mathrm{K}_{2 \mathrm{P}} 3.1$ were consistently observed [71]. This suggests that under unstimulated conditions either $\mathrm{K}_{2 \mathrm{P}} 9.1$ is endocytosed more readily than $\mathrm{K}_{2 \mathrm{P}} 3.1$ or indeed that it is retained within the endocytic pathway for longer (i.e. not shuttled back to the membrane or degraded). Both channels were found to colocalise with clathrin, and the number of endocytosed vesicles positive for both clathrin and either of the channels was dramatically reduced ( $\sim 50 \%$ reduction) following disruption of the CME pathway by dynasore (a powerful dynamin GTPase inhibitor which prevents fission of clathrin buds) [40, 71, 74, 102]. Continued channel internalisation following inhibition of clathrin bud fission suggests the possibility of these channels also utilising an alternate or clathrin independent pathway for internalisation [71]. Fractionation experiments performed by Inoue et al. support this view as they observed the majority of $\mathrm{K}_{2 \mathrm{P}} 9.1$ within a cell fraction in which transferrin receptor (a known cargo for CME) was also observed, but while $\mathrm{K}_{2 \mathrm{P}} 3.1$ was also observed within this fraction, it was also observed in a fraction containing flotillin which is suggestive of CIE [74]. Endocytosed channels were observed in both the recycling (Rab 11 positive vesicles) and degradative (Lamp1 positive) pathways in a number of studies using cells with either endogenous or heterologous channel expression [40, 71, 74, 102].

Stimulated $\mathrm{K}_{2 \mathrm{P}} 3.1$ internalisation has been demonstrated in a number of systems and is proposed to utilise specific motifs within the channel c-terminus. Nerve growth factor (NGF) activation of tyrosine kinase, $\operatorname{TrKA}$, has been proposed to induce CME of $\mathrm{K}_{2 \mathrm{P}} 3.1$ (but not $\mathrm{K}_{2 \mathrm{P}}$ 9.1) [74]. NGF treatment of either acutely isolated rat adrenal medulla cells which express $\mathrm{K}_{2 \mathrm{P}} 3.1$ channels or a rat adrenal medulla cell line from a pheochromocytoma (PC12 cells) which express both $\mathrm{K}_{2 \mathrm{P}} 3.1$ and $\mathrm{K}_{2 \mathrm{P}} 9.1$ resulted in decreased functional expression of $\mathrm{K}_{2 \mathrm{P}} 3.1$ and increased cytosolic expression of the channel [74]. Matsuoka et al. propose NGF stimulates $\mathrm{K}_{2 \mathrm{P}} 3.1$ internalisation through CME. However, the possibility that some of the observed effects following NGF treatment (decreased functional expression and increased cytosolic localisation of the channel) are due to disruption of channel forward transport is not completely ruled out. A di-leucine motif (LL263/264) within $\mathrm{K}_{2 \mathrm{P}} 3.1 \mathrm{c}$-terminus has been implicated in recruiting the channel to clathrin pits, while two c-terminal potential tyrosine motifs (YAEM or YSIP; Y317 and Y340 in rat $\mathrm{K}_{2 \mathrm{P}} 3.1$ ) were found not to contribute to the effect [74].

While Y317 was found not to be essential to NGF induced channel internalisation, a separate study found this motif to be critical to $\mathrm{K}_{2 \mathrm{P}} 3.1$ endocytosis in the human ortholog. Reningunta et al. demonstrate a direct interaction between a member of the Q-SNARE family (Q-soluble $\mathrm{N}$ ethylmaleimide-sensitive factor attachment protein receptor) syntaxin 8 (stx8) and $\mathrm{K}_{2 \mathrm{P}} 3.1$ and utilising recombinant expression systems demonstrate that stx 8 suppresses $\mathrm{K}_{2 \mathrm{P}} 3.1$ current and surface expression [102]. This interaction was not observed with either stx7 (another member of the SNARE family) or $\mathrm{K}_{2 \mathrm{P}} 9.1$. SNAREs operate by using a combination of various members of the Q and R-SNAREs to enable organelle-specific docking and fusion $[50,112]$. Regulation of $\mathrm{K}_{2 \mathrm{P}} 3.1$ surface expression by stx 8 is lost by ablating a region of interaction on stx8 or by disrupting CME. Disruption of the Y317 (critical to YAEV motif in human $\mathrm{K}_{2 \mathrm{P}} 3.1$ but absent from $\mathrm{K}_{2 \mathrm{P}}$ 9.1) disabled stx8-associated internalisation of $\mathrm{K}_{2 \mathrm{P}} 3.1$ [102]. This work further demonstrated that both $\mathrm{st} \times 8$ and $\mathrm{K}_{2 \mathrm{P}} 3.1$ are endocytosed in a cooperative manner and within the same vesicles. An attractive hypothesis proposed by the authors is that cooperative recruitment of $\mathrm{K}_{2 \mathrm{P}} 3.1$ and stx8 may influence their final destination through interaction with SNARE proteins localised to distinct subcellular compartments.

Protein kinase $\mathrm{C}(\mathrm{PKC})$ activation results in a decrease in $\mathrm{K}_{2 \mathrm{P}} 3.1$ current and cell surface expression [7, 40]. Human 
Table 1 Putative endocytic and sorting signaling motifs identified through in silico analysis of human $\mathrm{K}_{2 \mathrm{P}}$ family members. Residue number of critical or first residue within the human motif provided. Residues critical to motif recognition are in bold

\begin{tabular}{|c|c|c|c|c|c|}
\hline & Yхxф & DExxxL[LI] & KAC & Pro-rich & $\mathbf{L} \phi \times \phi[\mathbf{D E}]$ \\
\hline K2P1.1 (TWIK-1) & Y167FHL & DQVHI293I & D287KDED & & L261VVLE \\
\hline \multirow[t]{4}{*}{ K2P2.1 (TREK-1) } & Y254FVV & & & & \\
\hline & $\mathbf{Y}_{277 \mathrm{LDF}}$ & & & & \\
\hline & Y281KPV & & & & \\
\hline & $\mathbf{Y} 348 \mathrm{DKF}$ & & & & \\
\hline \multirow[t]{4}{*}{ K2P3.1 (TASK-1) } & Y138LLH & EHRAL263L & E252DEKRD & & \\
\hline & Y300AEV & & & & \\
\hline & $\mathbf{Y} 323 \mathrm{SIP}$ & & & & \\
\hline & Y353SDT & & & & \\
\hline K2P4.1 (TRAAK) & & & & P306 PPPCP & L344aFID \\
\hline \multirow[t]{4}{*}{ K2P5.1 (TREK-2) } & Y301NDL & & & & L413IFQD \\
\hline & Y410HPL & & & & L429SDEE \\
\hline & Y483EQL & & & & L443AGEE \\
\hline & & & & & L459NMGE \\
\hline K2P6.1 (TWIK-2) & Y308ASL & & D282EDDRVD & P272 PPCP & \\
\hline K2P9.1 (TASK-3) & & & E252DERRDAEE & & \\
\hline K2P10.1 (TREK-2) & Y478KTF & & D482EEKKEEE & & \\
\hline K2P12.1 (THIK-2) & & & D356SDAE & P6RPPP & \\
\hline K2P13.1 (THIK-1) & & & E335SDTD & & L291RKMD \\
\hline K2P15.1 (TASK-5) & & & & P261SPRPP & \\
\hline K2P16.1 (TALK-1) & & & & P301LPLP & \\
\hline \multirow[t]{2}{*}{ K2P17.1 (TASK-4) } & Y236PLW & & D295REPE & & \\
\hline & $\mathbf{Y}_{241} \mathbf{K N M}$ & & & & \\
\hline \multirow[t]{4}{*}{ K2P18.1 (TRESK) } & $\mathbf{Y}_{123} \mathrm{PVT}$ & & & & \\
\hline & $\mathbf{Y} 315 \mathrm{FCF}$ & & & & \\
\hline & Y343IIV & & & & \\
\hline & Y365KNV & & & & \\
\hline
\end{tabular}

embryonic kidney (HEK293T) cells heterologously expressing $\mathrm{K}_{2 \mathrm{P}} 3.1$ or rat cerebellar granule neuron (CGN) with endogenous expression of the channel treated with phorbol myristate acetate (PMA), a potent activator of PKC resulted in $\mathrm{K}_{2 \mathrm{P}} 3.1$ but not $\mathrm{K}_{2 \mathrm{P}} 9.1$ internalisation and localisation within distinct intracellular puncta [40]. Similarly, activation of mGluR had a comparable effect with reduced current and increased $\mathrm{K}_{2 \mathrm{P}} 3.1$ internalisation through CME. An REK motif analogous to a PKC-endocytosis motif identified and characterised in the dopamine transporter was found to be central to PKC-mediated endocytosis of $\mathrm{K}_{2 \mathrm{P}} 3.1$ but lacking in $\mathrm{K}_{2 \mathrm{P}} 9.1$ [40, 49, 68]. Gabriel et al. propose that this motif (SRERKLQYSIP) is similar to a mode II 14-3-3 binding motif and present evidence supporting the hypothesis that PKCmediated endocytosis requires 14-3-3 [40]. The rationale for targeting 14-3-3 $\beta$ alone or the identification of the requisite phosphorylation site were lacking but intriguingly 14-3-3 $\beta$ knockdown had a negative impact on both channel cell surface expression and current following PKC activation. These findings present interesting avenues to explore in terms of the role played by 14-3-3 in balancing $\mathrm{K}_{2 \mathrm{P}} 3.1$ forward transport and retrieval from the cell surface.

\section{How much can signaling motifs tell us?}

Endocytic signaling motifs are not conserved sequences but rather degenerate motifs in which two or three residues are critical for signal recognition. Recruitment to specific pathways is influenced by motif sequence; however, the ultimate fate of cargo following internalisation (degradation or recycling) is often determined not only by the pathway into which the protein is recruited but also by the affinity of adaptor proteins for variations within motif sequences [3, 110]. YXX $\phi$ motifs, for example are recognised by AP proteins and are essential for the rapid internalisation of cargo from the plasma membrane $[10,114]$. However, their function is not limited to endocytosis, since the same motif is implicated in the targeting of transmembrane proteins to lysosomes and lysosome-related organelles [10]. Evidence suggests that 
the variable residues $(\mathrm{XX} \phi)$ within the motif together with the phosphorylation state of the motif are central to recruiting specific AP isoforms and hence cargo destination. For example, YXX $\phi$ signals involved in lysosomal targeting customarily have a Gly preceding the critical Tyr, while acidic X residues result in lysosomal sorting $[10,14,114]$. This scenario is made all the more complicated by many transmembrane proteins containing more than one motif (Table 1) and the functionality of the motif being influenced by its position within the channel cytosolic domain and flanking residues. The impact of post-translational modifications within the motif and surrounding residues (ubiquitination, palmitoylation, phosphorylation, glycosylation) have also been well documented to impact motif usage and cargo fate $[17,20,77$, 94]. When examining the $K_{2 P}$ family of channels for prominent endocytic motifs, the majority of channels displayed an array of putative endocytic and sorting motifs (Table 1). Interestingly, none of the $\mathrm{K}_{2 \mathrm{P}}$ channels contained the tyrosine motif [FX]NPXY[FX], previously identified in other ion channels [35]. Many $\mathrm{K}_{2 \mathrm{P}}$ channels displayed multiple putative $\mathrm{Yxx} \phi$ motifs with up to four in some channels (Table 1). Many other membrane proteins contain a number of tyrosine motifs which on experimental analysis are not functionally relevant or may only be utilised under specific environmental conditions [17, 110]. Di-leucine or di-isoleucine motifs were only identified in $\mathrm{K}_{2 \mathrm{P}} 1.1$ and $\mathrm{K}_{2 \mathrm{P}} 3.1$ and both of these have been demonstrated to be functionally significant $[36,74]$. Putative short proline-rich domains, which are proposed to enable sorting between endosomes and the TGN, were identified in five $\mathrm{K}_{2 \mathrm{P}}$ channels, and for $\mathrm{K}_{2 \mathrm{P}} 15.1$ (TASK-5) and $\mathrm{K}_{2 \mathrm{P}} 16.1$ (TALK-1) these were the only putative endocytic sorting motifs identified (Table 1). While putative short acidic clusters (KAC) which are associated with protein retention within ARF6 positive recycling compartments were found in eight of the 14 human $\mathrm{K}_{2 \mathrm{P}}$ channels examined [44]. As only a handful of the predicted motifs have been experimentally determined, and motif usage depends on both protein and cellular context, functional motifs and the fate of channels due to possession of a signal motif will need to be explored experimentally.

Even with our limited understanding of the endocytic processes utilised to regulate $\mathrm{K}_{2 \mathrm{P}}$ channel functional expression, it is clear how versatile and important endocytosis could be in controlling the cell surface expression of such physiologically relevant proteins. As these channels enable $\mathrm{K}$ leakage from cells when they are expressed on the cell surface, their regulated removal from the plasma membrane and retention within recycling endosomes close to the cell surface appears a shrewd strategy to rapidly alter channel density in response to environmental stimuli. Equally, sorting these channels for destruction to regulate the optimal cell surface density either under unstimulated or stimulated conditions is a mode of regulation which if molecularly defined could have significant physiological and clinical implications.
Acknowledgments This work was supported by BBSRC grant BB/ J008168/1 to IO. Thanks to the past and present members of the IO lab for contribution to knowledge.

Open Access This article is distributed under the terms of the Creative Commons Attribution License which permits any use, distribution, and reproduction in any medium, provided the original author(s) and the source are credited.

\section{References}

1. Al-Awar O, Radhakrishna H, Powell NN, Donaldson JG (2000) Separation of membrane trafficking and actin remodeling functions of ARF6 with an effector domain mutant. Mol Cell Biol 20:5998-6007

2. Alloui A, Zimmermann K, Mamet J, Duprat F, Noel J, Chemin J, Guy N, Blondeau N, Voilley N, Rubat-Coudert C, Borsotto M, Romey G, Heurteaux C, Reeh P, Eschalier A, Lazdunski M (2006) TREK-1, a $\mathrm{K}+$ channel involved in polymodal pain perception. EMBO J 25:2368-2376

3. Arjonen A, Alanko J, Veltel S, Ivaska J (2012) Distinct recycling of active and inactive beta1 integrins. Traffic 13:610-625

4. Aryal P, Abd-Wahab F, Bucci G, Sansom MS, Tucker SJ (2014) A hydrophobic barrier deep within the inner pore of the TWIK-1 $\mathrm{K}_{2 \mathrm{P}}$ potassium channel. Nat Commun 5:4377

5. Balijepalli RC, Kamp TJ (2008) Caveolae, ion channels and cardiac arrhythmias. Prog Biophys Mol Biol 98:149-160

6. Balijepalli RC, Delisle BP, Balijepalli SY, Foell JD, Slind JK, Kamp TJ, January CT (2007) Kv11.1 (ERG1) K+ channels localize in cholesterol and sphingolipid enriched membranes and are modulated by membrane cholesterol. Channels (Austin) 1:263-272

7. Besana A, Barbuti A, Tateyama MA, Symes AJ, Robinson RB, Feinmark SJ (2004) Activation of protein kinase C epsilon inhibits the two-pore domain $\mathrm{K}+$ channel, TASK-1, inducing repolarization abnormalities in cardiac ventricular myocytes. J Biol Chem 279: 33154-33160

8. Bittner S, Budde T, Wiendl H, Meuth SG (2010) From the background to the spotlight: TASK channels in pathological conditions. Brain Pathol 20:999-1009

9. Bittner S, Ruck T, Fernandez-Orth J, Meuth SG (2014) TREKking the blood-brain-barrier. J Neuroimmune Pharmacol 9: 293-301

10. Bonifacino JS, Dell'Angelica EC (1999) Molecular bases for the recognition of tyrosine-based sorting signals. J Cell Biol 145:923-926

11. Bonifacino JS, Traub LM (2003) Signals for sorting of transmembrane proteins to endosomes and lysosomes. Annu Rev Biochem 72:395-447

12. Bonifacino JS, Rojas R (2006) Retrograde transport from endosomes to the trans-Golgi network. Nat Rev Mol Cell Biol 7: 568-579

13. Bonifacino JS, Marks MS, Ohno H, Kirchhausen T (1996) Mechanisms of signal-mediated protein sorting in the endocytic and secretory pathways. Proc Assoc Am Physicians 108:285-295

14. Braulke T, Bonifacino JS (2009) Sorting of lysosomal proteins. Biochim Biophys Acta 1793:605-614

15. Brown FD, Rozelle AL, Yin HL, Balla T, Donaldson JG (2001) Phosphatidylinositol 4,5-bisphosphate and ARF6-regulated membrane traffic. J Cell Biol 154:1007-1017

16. Buckler KJ (2010) Two-pore domain $\mathrm{k}(+)$ channels and their role in chemoreception. Adv Exp Med Biol 661:15-30

17. Canto I, Trejo J (2013) Palmitoylation of protease-activated receptor-1 regulates adaptor protein complex-2 and -3 interaction with tyrosine-based motifs and endocytic sorting. J Biol Chem 288: $15900-15912$ 
18. Carlo AS, Nykjaer A, Willnow TE (2014) Sorting receptor sortilin-a culprit in cardiovascular and neurological diseases. J Mol Med (Berl) 92:905-911

19. Carlton J, Bujny M, Rutherford A, Cullen P (2005) Sorting nexins - unifying trends and new perspectives. Traffic 6:75-82

20. Chen B, Dores MR, Grimsey N, Canto I, Barker BL, Trejo J (2011) Adaptor protein complex-2 (AP-2) and epsin-1 mediate proteaseactivated receptor- 1 internalization via phosphorylation- and ubiquitination-dependent sorting signals. J Biol Chem 286:4076040770

21. Chen WJ, Goldstein JL, Brown MS (1990) NPXY, a sequence often found in cytoplasmic tails, is required for coated pit-mediated internalization of the low density lipoprotein receptor. J Biol Chem 265:3116-3123

22. Conner SD, Schmid SL (2003) Regulated portals of entry into the cell. Nature 422:37-44

23. Czirjak G, Enyedi P (2002) Formation of functional heterodimers between the TASK-1 and TASK-3 two-pore domain potassium channel subunits. J Biol Chem 277:5426-5432

24. Czirjak G, Toth ZE, Enyedi P (2004) The two-pore domain K+ channel, TRESK, is activated by the cytoplasmic calcium signal through calcineurin. J Biol Chem 279:18550-18558

25. D'Souza-Schorey C, Li G, Colombo MI, Stahl PD (1995) A regulatory role for ARF6 in receptor-mediated endocytosis. Science 267: $1175-1178$

26. Decressac S, Franco M, Bendahhou S, Warth R, Knauer S, Barhanin J, Lazdunski M, Lesage F (2004) ARF6-dependent interaction of the TWIK1 K+ channel with EFA6, a GDP/GTP exchange factor for ARF6. EMBO Rep 5:1171-1175

27. Deng PY, Poudel SK, Rojanathammanee L, Porter JE, Lei S (2007) Serotonin inhibits neuronal excitability by activating two-pore domain $\mathrm{k}+$ channels in the entorhinal cortex. Mol Pharmacol 72:208-218

28. Doherty GJ, McMahon HT (2009) Mechanisms of endocytosis. Annu Rev Biochem 78:857-902

29. Donaldson JG, Porat-Shliom N, Cohen LA (2009) Clathrinindependent endocytosis: a unique platform for cell signaling and PM remodeling. Cell Signal 21:1-6

30. Doray B, Misra S, Qian Y, Brett TJ, Kornfeld S (2012) Do GGA adaptors bind internal DXXLL motifs? Traffic 13:1315-1325

31. Duprat F, Lesage F, Fink M, Reyes R, Heurteaux C, Lazdunski M (1997) TASK, a human background $\mathrm{K}+$ channel to sense external $\mathrm{pH}$ variations near physiological $\mathrm{pH}$. EMBO J 16:5464-5471

32. Enyedi P, Czirjak G (2010) Molecular background of leak K+ currents: two-pore domain potassium channels. Physiol Rev 90:559-605

33. Enyedi P, Braun G, Czirjak G (2012) TRESK: the lone ranger of twopore domain potassium channels. Mol Cell Endocrinol 353:75-81

34. Eva R, Crisp S, Marland JR, Norman JC, Kanamarlapudi V, ffrenchConstant C, Fawcett JW (2012) ARF6 directs axon transport and traffic of integrins and regulates axon growth in adult DRG neurons. J Neurosci 32:10352-10364

35. Fang L, Garuti R, Kim BY, Wade JB, Welling PA (2009) The ARH adaptor protein regulates endocytosis of the ROMK potassium secretory channel in mouse kidney. J Clin Invest 119:3278-3289

36. Feliciangeli S, Tardy MP, Sandoz G, Chatelain FC, Warth R, Barhanin J, Bendahhou S, Lesage F (2010) Potassium channel silencing by constitutive endocytosis and intracellular sequestration. J Biol Chem 285:4798-4805

37. Feliciangeli S, Bendahhou S, Sandoz G, Gounon P, Reichold M, Warth R, Lazdunski M, Barhanin J, Lesage F (2007) Does sumoylation control $\mathrm{K}_{2 \mathrm{P}} 1 /$ TWIK1 background $\mathrm{K}+$ channels? Cell 130:563-569

38. Franks NP, Honore E (2004) The TREK $K_{2 P}$ channels and their role in general anaesthesia and neuroprotection. Trends Pharmacol Sci 25:601-608

39. Furthauer M, Smythe E (2014) Systems dynamics in endocytosis. Traffic 15:338-346
40. Gabriel L, Lvov A, Orthodoxou D, Rittenhouse AR, Kobertz WR, Melikian HE (2012) The acid-sensitive, anesthetic-activated potassium leak channel, KCNK3, is regulated by 14-3-3beta-dependent, protein kinase C (PKC)-mediated endocytic trafficking. J Biol Chem 287:32354-32366

41. Girard C, Tinel N, Terrenoire C, Romey G, Lazdunski M, Borsotto $\mathrm{M}(2002) \mathrm{p} 11$, an annexin II subunit, an auxiliary protein associated with the background K+ channel, TASK-1. EMBO J 21:4439-4448

42. Glebov OO, Bright NA, Nichols BJ (2006) Flotillin-1 defines a clathrin-independent endocytic pathway in mammalian cells. Nat Cell Biol 8:46-54

43. Goldstein SA, Bockenhauer D, O'Kelly I, Zilberberg N (2001) Potassium leak channels and the KCNK family of two-P-domain subunits. Nat Rev Neurosci 2:175-184

44. Gong Q, Weide M, Huntsman C, Xu Z, Jan LY, Ma D (2007) Identification and characterization of a new class of trafficking motifs for controlling clathrin-independent internalization and recycling. J Biol Chem 282:13087-13097

45. Gonnord P, Blouin CM, Lamaze C (2012) Membrane trafficking and signaling: two sides of the same coin. Semin Cell Dev Biol 23: 154-164

46. Gurney A, Manoury B (2009) Two-pore potassium channels in the cardiovascular system. Eur Biophys J 38:305-318

47. Heitzmann D, Derand R, Jungbauer S, Bandulik S, Sterner C, Schweda F, El WA, Lalli E, Guy N, Mengual R, Reichold M, Tegtmeier I, Bendahhou S, Gomez-Sanchez CE, Aller MI, Wisden W, Weber A, Lesage F, Warth R, Barhanin J (2008) Invalidation of TASK1 potassium channels disrupts adrenal gland zonation and mineralocorticoid homeostasis. EMBO J 27:179-187

48. Heurteaux C, Lucas G, Guy N, El YM, Thummler S, Peng XD, Noble F, Blondeau N, Widmann C, Borsotto M, Gobbi G, Vaugeois JM, Debonnel G, Lazdunski M (2006) Deletion of the background potassium channel TREK-1 results in a depression-resistant phenotype. Nat Neurosci 9:1134-1141

49. Holton KL, Loder MK, Melikian HE (2005) Nonclassical, distinct endocytic signals dictate constitutive and PKC-regulated neurotransmitter transporter internalization. Nat Neurosci 8:881-888

50. Hong W (2005) SNAREs and traffic. Biochim Biophys Acta 1744: 493-517

51. Honing S, Ricotta D, Krauss M, Spate K, Spolaore B, Motley A, Robinson M, Robinson C, Haucke V, Owen DJ (2005) Phosphatidylinositol-(4,5)-bisphosphate regulates sorting signal recognition by the clathrin-associated adaptor complex AP2. Mol Cell 18:519-531

52. Honore $\mathrm{E}$ (2007) The neuronal background $\mathrm{K}_{2 \mathrm{P}}$ channels: focus on TREK1. Nat Rev Neurosci 8:251-261

53. Hsu VW, Prekeris R (2010) Transport at the recycling endosome. Curr Opin Cell Biol 22:528-534

54. Johannes L, Wunder C (2011) Retrograde transport: two (or more) roads diverged in an endosomal tree? Traffic 12:956-962

55. Jovanovic OA, Brown FD, Donaldson JG (2006) An effector domain mutant of ARF6 implicates phospholipase D in endosomal membrane recycling. Mol Biol Cell 17:327-335

56. Kennard LE, Chumbley JR, Ranatunga KM, Armstrong SJ, Veale EL, Mathie A (2005) Inhibition of the human two-pore domain potassium channel, TREK-1, by fluoxetine and its metabolite norfluoxetine. Br J Pharmacol 144:821-829

57. Keyel PA, Mishra SK, Roth R, Heuser JE, Watkins SC, Traub LM (2006) A single common portal for clathrin-mediated endocytosis of distinct cargo governed by cargo-selective adaptors. Mol Biol Cell 17:4300-4317

58. Kim Y, Bang H, Kim D (2000) TASK-3, a new member of the tandem pore $\mathrm{K}(+)$ channel family. J Biol Chem 275:9340-9347

59. Kobayashi H, Fukuda M (2013) ARF6, Rab11 and transferrin receptor define distinct populations of recycling endosomes. Commun Integr Biol 6:e25036 
60. Koumakpayi IH, Le PC, Delvoye N, Saad F, Mes-Masson AM (2011) Macropinocytosis inhibitors and ARF6 regulate ErbB3 nuclear localization in prostate cancer cells. Mol Carcinog 50: 901-912

61. Krauss M, Kinuta M, Wenk MR, De CP, Takei K, Haucke V (2003) ARF6 stimulates clathrin/AP-2 recruitment to synaptic membranes by activating phosphatidylinositol phosphate kinase type $\mathrm{I} \gamma$. J Cell Biol 162:113-124

62. Lafer EM (2002) Clathrin-protein interactions. Traffic 3:513-520

63. Lafreniere RG, Rouleau GA (2011) Migraine: role of the TRESK two-pore potassium channel. Int J Biochem Cell Biol 43:1533-1536

64. Lakadamyali M, Rust MJ, Zhuang X (2006) Ligands for clathrinmediated endocytosis are differentially sorted into distinct populations of early endosomes. Cell 124:997-1009

65. Lesage F, Lazdunski M (2000) Molecular and functional properties of two-pore-domain potassium channels. Am J Physiol Renal Physiol 279:F793-F801

66. Lesage F, Guillemare E, Fink M, Duprat F, Lazdunski M, Romey G, Barhanin J (1996) TWIK-1, a ubiquitous human weakly inward rectifying $\mathrm{K}+$ channel with a novel structure. EMBO J 15:1004 1011

67. Lesage F, Lauritzen I, Duprat F, Reyes R, Fink M, Heurteaux C, Lazdunski M (1997) The structure, function and distribution of the mouse TWIK-1 K+ channel. FEBS Lett 402:28-32

68. Loder MK, Melikian HE (2003) The dopamine transporter constitutively internalizes and recycles in a protein kinase C-regulated manner in stably transfected PC12 cell lines. J Biol Chem 278: 22168-22174

69. Lotshaw DP (2007) Biophysical, pharmacological, and functional characteristics of cloned and native mammalian two-pore domain $\mathrm{K}+$ channels. Cell Biochem Biophys 47:209-256

70. Maldonado-Baez L, Williamson C, Donaldson JG (2013) Clathrinindependent endocytosis: a cargo-centric view. Exp Cell Res 319: 2759-2769

71. Mant A, Williams S, O’Kelly I (2013) Acid sensitive background potassium channels $\mathrm{K}_{2 \mathrm{P}} 3.1$ and $\mathrm{K}_{2 \mathrm{P}} 9.1$ undergo rapid dynamindependent endocytosis. Channels (Austin) 7:288-302

72. Mant A, Williams S, Roncoroni L, Lowry E, Johnson D, O'Kelly I (2013) N-glycosylation-dependent control of functional expression of background potassium channels $\mathrm{K}_{2 \mathrm{P}} 3.1$ and $\mathrm{K}_{2 \mathrm{P}} 9.1$. J Biol Chem 288:3251-3264

73. Mathie A, Rees KA, El Hachmane MF, Veale EL (2010) Trafficking of neuronal two pore domain potassium channels. Curr Neuropharmacol 8:276-286

74. Matsuoka H, Harada K, Nakamura J, Inoue M (2013) Nerve growth factor-induced endocytosis of TWIK-related acid-sensitive $\mathrm{K}(+) 1$ channels in adrenal medullary cells and PC12 cells. Pflugers Arch 465:1051-1064

75. Mayor S, Pagano RE (2007) Pathways of clathrin-independent endocytosis. Nat Rev Mol Cell Biol 8:603-612

76. Mazella J, Petrault O, Lucas G, Deval E, Beraud-Dufour S, Gandin C, El-Yacoubi M, Widmann C, Guyon A, Chevet E, Taouji S, Conductier G, Corinus A, Coppola T, Gobbi G, Nahon JL, Heurteaux C, Borsotto M (2010) Spadin, a sortilin-derived peptide, targeting rodent TREK-1 channels: a new concept in the antidepressant drug design. PLoS Biol 8:e1000355

77. McCormick PJ, Dumaresq-Doiron K, Pluviose AS, Pichette V, Tosato G, Lefrancois S (2008) Palmitoylation controls recycling in lysosomal sorting and trafficking. Traffic 9:1984-1997

78. McMahon HT, Boucrot E (2011) Molecular mechanism and physiological functions of clathrin-mediated endocytosis. Nat Rev Mol Cell Biol 12:517-533

79. Mishra SK, Watkins SC, Traub LM (2002) The autosomal recessive hypercholesterolemia (ARH) protein interfaces directly with the clathrin-coat machinery. Proc Natl Acad Sci U S A 99:1609916104
80. Mishra SK, Keyel PA, Hawryluk MJ, Agostinelli NR, Watkins SC, Traub LM (2002) Disabled-2 exhibits the properties of a cargo-selective endocytic clathrin adaptor. EMBO J 21:49154926

81. Nakai W, Kondo Y, Saitoh A, Naito T, Nakayama K, Shin HW (2013) ARF1 and ARF4 regulate recycling endosomal morphology and retrograde transport from endosomes to the Golgi apparatus. Mol Biol Cell 24:2570-2581

82. Nichols BJ, Lippincott-Schwartz J (2001) Endocytosis without clathrin coats. Trends Cell Biol 11:406-412

83. Nie X, Arrighi I, Kaissling B, Pfaff I, Mann J, Barhanin J, Vallon V (2005) Expression and insights on function of potassium channel TWIK-1 in mouse kidney. Pflugers Arch 451:479-488

84. Noel J, Sandoz G, Lesage F (2011) Molecular regulations governing TREK and TRAAK channel functions. Channels (Austin) 5:402-409

85. O'Kelly I, Goldstein SA (2008) Forward transport of $\mathrm{K}_{2 \mathrm{P}} 3.1$ : mediation by 14-3-3 and COPI, modulation by p11. Traffic 9:72-78

86. O'Kelly I, Butler MH, Zilberberg N, Goldstein SA (2002) Forward transport. 14-3-3 binding overcomes retention in endoplasmic reticulum by dibasic signals. Cell 111:577-588

87. Ohno H (2006) Clathrin-associated adaptor protein complexes. J Cell Sci 119:3719-3721

88. Palacios F, Schweitzer JK, Boshans RL, D'Souza-Schorey C (2002) ARF6-GTP recruits Nm23-H1 to facilitate dynamin-mediated endocytosis during adherens junctions disassembly. Nat Cell Biol 4: 929-936

89. Parton RG, del Pozo MA (2013) Caveolae as plasma membrane sensors, protectors and organizers. Nat Rev Mol Cell Biol 14:98112

90. Patel AJ, Honore E, Lesage F, Fink M, Romey G, Lazdunski M (1999) Inhalational anesthetics activate two-pore-domain background $\mathrm{K}+$ channels. Nat Neurosci 2:422-426

91. Pelkmans L, Zerial M (2005) Kinase-regulated quantal assemblies and kiss-and-run recycling of caveolae. Nature 436:128-133

92. Perrais D, Merrifield CJ (2005) Dynamics of endocytic vesicle creation. Dev Cell 9:581-592

93. Platta HW, Stenmark H (2011) Endocytosis and signaling. Curr Opin Cell Biol 23:393-403

94. Ponimaskin E, Dumuis A, Gaven F, Barthet G, Heine M, Glebov K, Richter DW, Oppermann M (2005) Palmitoylation of the 5hydroxytryptamine4a receptor regulates receptor phosphorylation, desensitization, and beta-arrestin-mediated endocytosis. Mol Pharmacol 67:1434-1443

95. Prigent M, Dubois T, Raposo G, Derrien V, Tenza D, Rosse C, Camonis J, Chavrier P (2003) ARF6 controls post-endocytic recycling through its downstream exocyst complex effector. J Cell Biol 163:1111-1121

96. Radhakrishna H, Donaldson JG (1997) ADP-ribosylation factor 6 regulates a novel plasma membrane recycling pathway. J Cell Biol 139:49-61

97. Radhakrishna H, Al-Awar O, Khachikian Z, Donaldson JG (1999) ARF6 requirement for Rac ruffling suggests a role for membrane trafficking in cortical actin rearrangements. J Cell Sci 112(Pt 6): 855-866

98. Rajan S, Plant LD, Rabin ML, Butler MH, Goldstein SA (2005) Sumoylation silences the plasma membrane leak $\mathrm{K}+$ channel $\mathrm{K}_{2 \mathrm{P}} 1$. Cell 121:37-47

99. Rajan S, Wischmeyer E, Xin LG, Preisig-Muller R, Daut J, Karschin A, Derst C (2000) TASK-3, a novel tandem pore domain acid-sensitive $\mathrm{K}+$ channel. an extracellular histiding as $\mathrm{pH}$ sensor. J Biol Chem 275:16650-16657

100. Rajan S, Preisig-Muller R, Wischmeyer E, Nehring R, Hanley PJ, Renigunta V, Musset B, Schlichthorl G, Derst C, Karschin A, Daut J (2002) Interaction with 14-3-3 proteins promotes functional expression of the potassium channels TASK-1 and TASK-3. J Physiol 545: $13-26$ 
101. Rankovic M, Jacob L, Rankovic V, Brandenburg LO, Schroder H, Hollt V, Koch T (2009) ADP-ribosylation factor 6 regulates muopioid receptor trafficking and signaling via activation of phospholipase D2. Cell Signal 21:1784-1793

102. Renigunta V, Fischer T, Zuzarte M, Kling S, Zou X, Siebert K, Limberg MM, Rinne S, Decher N, Schlichthorl G, Daut J (2014) Cooperative endocytosis of the endosomal SNARE protein syntaxin-8 and the potassium channel TASK-1. Mol Biol Cell 25: $1877-1891$

103. Renigunta V, Yuan H, Zuzarte M, Rinne S, Koch A, Wischmeyer E, Schlichthorl G, Gao Y, Karschin A, Jacob R, Schwappach B, Daut J, Preisig-Muller R (2006) The retention factor p11 confers an endoplasmic reticulum-localization signal to the potassium channel TASK-1. Traffic 7:168-181

104. Rous BA, Reaves BJ, Ihrke G, Briggs JA, Gray SR, Stephens DJ, Banting G, Luzio JP (2002) Role of adaptor complex AP-3 in targeting wild-type and mutated CD63 to lysosomes. Mol Biol Cell 13:1071-1082

105. Sandoz G, Tardy MP, Thummler S, Feliciangeli S, Lazdunski M, Lesage F (2008) Mtap2 is a constituent of the protein network that regulates twik-related $\mathrm{K}+$ channel expression and trafficking. $\mathrm{J}$ Neurosci 28:8545-8552

106. Sandoz G, Thummler S, Duprat F, Feliciangeli S, Vinh J, Escoubas P, Guy N, Lazdunski M, Lesage F (2006) AKAP150, a switch to convert mechano-, $\mathrm{pH}$ - and arachidonic acid-sensitive TREK K(+) channels into open leak channels. EMBO J 25:5864-5872

107. Sandvig K, Torgersen ML, Raa HA, van Deurs DB (2008) Clathrinindependent endocytosis: from nonexisting to an extreme degree of complexity. Histochem Cell Biol 129:267-276

108. Sano Y, Inamura K, Miyake A, Mochizuki S, Kitada C, Yokoi H, Nozawa K, Okada H, Matsushime H, Furuichi K (2003) A novel two-pore domain $\mathrm{K}+$ channel, TRESK, is localized in the spinal cord. J Biol Chem 278:27406-27412

109. Seaman MN (2008) Endosome protein sorting: motifs and machinery. Cell Mol Life Sci 65:2842-2858

110. Sigismund S, Argenzio E, Tosoni D, Cavallaro E, Polo S, Di Fiore PP (2008) Clathrin-mediated internalization is essential for sustained EGFR signaling but dispensable for degradation. Dev Cell 15:209-219
111. Teasdale RD, Collins BM (2012) Insights into the PX (phoxhomology) domain and SNX (sorting nexin) protein families: structures, functions and roles in disease. Biochem J 441:39-59

112. Teng FY, Wang Y, Tang BL (2001) The syntaxins. Genome Biol 2: reviews3012-3012.7

113. Traub LM (2005) Common principles in clathrin-mediated sorting at the Golgi and the plasma membrane. Biochim Biophys Acta $1744: 415-437$

114. Traub LM, Bonifacino JS (2013) Cargo recognition in clathrinmediated endocytosis. Cold Spring Harb Perspect Biol 5:a016790

115. Vaegter CB, Jansen P, Fjorback AW, Glerup S, Skeldal S, Kjolby M, Richner M, Erdmann B, Nyengaard JR, Tessarollo L, Lewin GR, Willnow TE, Chao MV, Nykjaer A (2011) Sortilin associates with Trk receptors to enhance anterograde transport and neurotrophin signaling. Nat Neurosci 14:54-61

116. van Vliet C, Thomas EC, Merino-Trigo A, Teasdale RD, Gleeson PA (2003) Intracellular sorting and transport of proteins. Prog Biophys Mol Biol 83:1-45

117. Wang W, Putra A, Schools GP, Ma B, Chen H, Kaczmarek LK, Barhanin J, Lesage F, Zhou M (2013) The contribution of TWIK-1 channels to astrocyte $\mathrm{K}(+)$ current is limited by retention in intracellular compartments. Front Cell Neurosci 7:246

118. Willnow TE, Petersen CM, Nykjaer A (2008) VPS10P-domain receptors - regulators of neuronal viability and function. Nat Rev Neurosci 9:899-909

119. Xue J, Graham ME, Novelle AE, Sue N, Gray N, McNiven MA, Smillie KJ, Cousin MA, Robinson PJ (2011) Calcineurin selectively docks with the dynamin Ixb splice variant to regulate activity-dependent bulk endocytosis. J Biol Chem 286:3029530303

120. Zhang Q, Calafat J, Janssen H, Greenberg S (1999) ARF6 is required for growth factor- and rac-mediated membrane ruffling in macrophages at a stage distal to rac membrane targeting. Mol Cell Biol 19:8158-8168

121. Zuzarte M, Heusser K, Renigunta V, Schlichthorl G, Rinne S, Wischmeyer E, Daut J, Schwappach B, Preisig-Muller R (2009) Intracellular traffic of the K+ channels TASK-1 and TASK-3: role of $\mathrm{N}$ - and C-terminal sorting signals and interaction with 14-3-3 proteins. J Physiol 587:929-952 